\title{
Addressing Fractional Dimensionality in the Application of Weather Index Insurance and Climate Risk Financing in Agricultural Development: A Dynamic Triggering Approach
}

\author{
CAlum G. Turvey \\ Cornell University, Ithaca, New York \\ Apurba SheE AND ANA MARR \\ University of Greenwich, Chatham Maritime, United Kingdom
}

(Manuscript received 25 January 2019, in final form 24 June 2019)

\begin{abstract}
Climate risk financing programs in agriculture have caught the attention of researchers and policy makers over the last decade. Weather index insurance has emerged as a promising market-based risk financing mechanism. However, to develop a suitable weather index insurance mechanism it is essential to incorporate the distribution of underlying weather and climate risks to a specific event model that can minimize intraseasonal basis risk. In this paper we investigate the erratic nature of rainfall patterns in Kenya using Climate Hazards Group Infrared Precipitation with Station Data (CHIRPS) rainfall data from 1983 to 2017. We find that the patterns of rainfall are fractional, both erratic and persistent, which is consistent with the Noah and Joseph effects that are well known in mathematics. The erratic nature of rainfall emerges from the breakdown of the convergence to a normal distribution. Instead we find that the distribution about the average is approximately lognormal, with an almost $50 \%$ higher chance of deficit rainfall below the mean than adequate rainfall above the mean. We find that the rainfall patterns obey the Hurst law and that the measured Hurst coefficients for seasonal rainfall pattern across all years range from a low of 0.137 to a high above 0.685 . To incorporate the erratic and persistent nature of seasonal rainfall, we develop a new approach to weather index insurance based upon the accumulated rainfall in any 21-day period falling below $60 \%$ of the long-term average for that same 21-day period. We argue that this approach is more satisfactory to matching drought conditions within and between various phenological stages of growth.
\end{abstract}

\section{Introduction}

All too often, scholars and practitioners examining weather data for the purpose of developing weather index insurance (WII) make the assumption, or presumption, that the data are Gaussian and Markovian, meaning that day-over-day or season-over-season measures are independent and uncorrelated. For example, the index insurance designs presented in Mahul and Skees (2007) for livestock insurance in Mongolia, in Khalil et al. (2007) for El Niño insurance in Peru, in Makaudze and Miranda (2010) for drought insurance in Zimbabwe, and in Chantarat et al. (2013) and Woodard et al. (2016) for livestock insurance in Kenya used seasonal accumulation of weather indexes for pricing insurance and assumed an independent relationship

Corresponding author: Apurba Shee, a.shee@gre.ac.uk between sequential time series weather data. This may not be the wisest approach. When meteorologists speak of weather "patterns" they are not making references to sequences of independent events but rather to events of some duration that in one way or another are correlated. This in itself should be warning enough that weather patterns do not follow the Gaussian variance law $\operatorname{Var}\left(x_{t+S}-x_{t}\right)=\operatorname{Var}\left(x_{t}-x_{t-1}\right) S^{1 / 2}$ but rather follow a form of Hurst's law, $\operatorname{Var}\left(x_{t+S}-x_{t}\right)=\operatorname{Var}\left(x_{t}-x_{t-1}\right) S^{2 H}$, where $H$, referred to as Hurst's coefficient, is a nonarbitrary constant (Hurst 1951). As will be shown presently, $H$ captures persistence in negative $(H<0.5)$ and positive $(H>0.5)$ correlations across the time domain. Only for $H=0.5$ does the Gauss-Markov assumption hold. The implication of this fact for climate-based WII is evident. Should the Gauss-Markov assumption be used in the pricing of WII it will overestimate the variance for $H<0.5$ and underestimate the variance for 
$H>0.5$. The direct corollary is that the actuarial value of WII will be too high for $H<0.5$ and too low for $H>0.5$.

Fractional dimensionality of weather events should be an important consideration for capturing weather extremities. In Hurst's (1951) original work on hydrology he was examining the water flow of the Nile River in the context of engineering dams. These dams had to withhold the extremes of water flow. In Hurst's rescaledrange approach (which is similar to but different from our Brownian approach) he discovered that the flow of water varied proportionately to $d^{H}$ with $0.5<H<1$, and not $d^{0.5}$ as had previously been thought (Mandelbrot and Van Ness 1968). With coefficients of $H \approx 0.7$ the upper-bound extremities of water flow were much higher than expected, and consequently the dams had to be engineered to withhold low-frequency, extreme events that exceeded the flows observed to that date. One can imagine now if the variable $d$ were otherwise interpreted as cumulative rainfall and followed a $d^{H}$ law, then the actuarial measures of extreme rainfall would need to account for the fractional extremities, even if those extremes had not previously been observed. We believe these considerations to be important in the development of a sustainable WII product and explore them in this paper in the context of an operational insurance-linked credit in Kenya.

In Mandelbrot and Wallis's classical exploration into the fractional properties of water flow (Mandelbrot and Wallis 1968), they engagingly introduce the problem with biblical references to the "Noah" effect, which refers to the fact that precipitation can have very sudden disruptions, and the "Joseph" effect, in which precipitation in a period can have correlation with precipitation in the distant past. The extremities of rainfall are bounded from below at zero and are theoretically limitless from above, although not unlikely without bound. To what extent either the Noah effect or the Joseph effect has an impact on the human or natural condition is determined by the mathematical mix of frequency, duration, and intensity and with respect to the ecology under consideration.

In the context of agricultural weather insurance-the broader subject matter of this paper-these climate considerations are important. The context of this paper is the design of a WII product that can be imbedded into a credit product to manage drought-related agricultural risk as well as to provide access to credit to smallholder farmers. In this way we make two advances to the literature and practice in the design of WII and the application to climate risk financing. On this latter point, insurance-linked or bundled credit products have been promoted by a number of scholars including
Skees and Barnett (2006), Giné and Yang (2009), Carter et al. (2011), Karlan et al. (2011), Miranda and GonzalezVega (2011), Collier et al. (2011), Shee and Turvey (2012), Shee et al. (2015), Marr et al. (2016), Pelka et al. (2015), Carter et al. (2016), von Negenborn et al. (2018), and Mishra et al. (2018). Clarke and Grenham (2013) and Jensen et al. (2016) point out that basis risk limits farmers' investment in WII. In a recent article, Muller et al. (2017) argue the need of careful consideration of local socioecological context when developing an agricultural risk transfer product. An insurance-linked credit mechanism responds to several of the critiques offered by Binswanger-Mkhize (2012), who argue that, until the problems of basis risk and credit access can be resolved, the advancements of various forms of weather insurance as a promising mechanism to transfer risk from poor farmers to the insurance markets on a large scale might be overstated. Although the promise of index insurance in alleviating poverty traps has been widely discussed (e.g., Barrett et al. 2007), and some successes have been reported (e.g., Chantarat et al. 2017), the Binswanger-Mkhize critique should not be treated lightly.

In the autumn of 2017, our research group piloted an insurance-linked credit product in Machakos County in Kenya, with loan indemnities linked to long and short rains (Shee et al. 2019). Our study area comprises five subcounties in Machakos County and is spread over 13 locations as specified in Fig. 1. This is a semiarid and hilly terrain area that receives very low annual rainfall of around $700 \mathrm{~mm}$ per year, with average rainfall in the long and short rain seasons being 315 and $266 \mathrm{~mm}$, respectively (Government of Kenya 2014). Because of this semiarid climate, agriculture is practiced by smallholder farmers, with maize being the main food crop.

In our efforts, it became abundantly clear that standard approaches to WII based on seasonal cumulative rainfall were inadequate in measuring within-season risk. To address the phenological problem we develop a rainfall insurance based on what we refer to as a dynamic trigger. This trigger establishes an indemnity if the accumulated rainfall in any 21 -day period is below $60 \%$ of the historical average rainfall in that same 21-day period for a given year. This will be explored in more depth later, but when we examined the "average" path of overlapping 21-day measures and took the deviation of each year's equivalent measure we found the distribution of the difference to be nonnormal. Indeed, we find it to be close to a lognormal distribution with the probability that below-normal rainfall in our study region was approximately $50 \%$ more likely than above normal rainfall. The failure of normality suggests also a failure in the GaussMarkov assumption normally assumed in a first-guess 


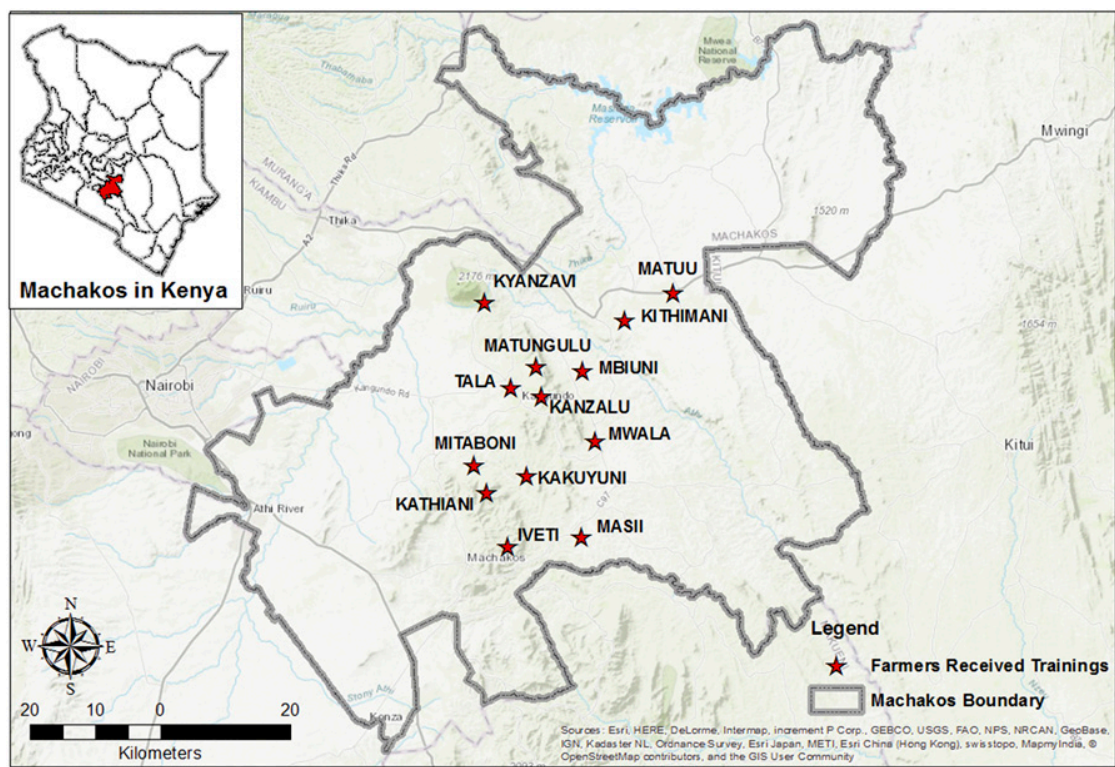

FIG. 1. Map of study area-Machakos County in Kenya.

approach to statistical assumption. This also comes with a possible failure in the independence assumption and Brownian presumption of the historical time path of our data series-as limited as it is. As Mandelbrot and Wallis (1968) point out, the failure to recognize the nonMarkov possibilities would greatly underestimate the duration and intensity of the longest drought.

We explore fractional weather pattern by measuring Hurst coefficients within the Mandelbrot-Wallis framework to investigate non-Markov possibilities. Our analysis of fractional weather patterns will encourage researchers who develop or evaluate the many varieties of WII models to treat with greater seriousness the combined Noah and Joseph effects (sudden reversal and long persistence in weather pattern). Of course, weather patterns are mixed in terms of frequency, duration, and intensity, but one clear implication of our investigation is that fractional patterns within an agricultural growing season should not be ignored and that within-season WII should be designed with multiple events that traverse the various stages of phenological growth. Our approach to dynamic triggering of multiple events in designing agricultural WII is an important contribution of this paper to incorporate fractionality of weather and to reduce intertemporal basis risk in WII.

The next section discusses the literature on specific events and phenological growth in weather index insurance. Next, we develop with greater granularity the statistical genesis of the Hurst coefficient within the Mandelbrot-Wallis framework. This is followed by a description of the fractional patterning of rainfall in Machakos where we provide Hurst measures. We then provide a possible solution to fractional rainfall patterns by providing a new structure for within-season WII based on a dynamic trigger approach that traverses phenological growth stages to provide up to four indemnifiable events across the growing season. Section 5 concludes with broader policy implications.

\section{Specific events and phenological growth in weather index insurance}

Turvey (2001) notes that specific weather events can be linked to insurance coverage against crop production, which is usually affected by phenological growth dependent on weather conditions such as rainfall, temperature, and soil moisture. Norton et al. (2012), for example, suggest that weather insurance ought not to be viewed as a perfect substitute for multiple peril crop insurance, but as a risk-transfer instrument that should be specifically targeted toward covariate events that are weathersensitive such as Karnal Bunt and Stewart's disease. Particular weather conditions can also give rise to insect infestations for which Richards et al. (2006) suggest so-called bug options.

The weakness in the application of weather insurance in both developing and developed agricultural economies is the existence of "basis" risk. In general terms, basis risk refers to the observed variability in an insured asset that is seemingly uncorrelated, or weakly correlated, with a proxy measure of risk. Basis risk can arise spatially by distance, altitude, and geomorphology (Norton et al. 2012; Heimfarth et al. 2012; Heimfarth and Musshoff 2011; Woodard and Garcia 2008). 
However, it is increasingly being recognized that basis risk also arises with the patterning of weather within a season at a specific location. Intraseasonal basis risk deals with the failure of a specified index to adequately capture within-season variability, leading to excessive type-I or type-II errors. Type-I error refers to insurance payments when no crop damage is observed, whereas type-II error refers to situations in which crop damage is observed but no indemnity is paid. In a more general way we can say that added specificity to the weather index ought to reduce both type-I and type-II error, at least in probabilistic terms. One approach to doing this is to recognize that, rather than a single index for an entire season (e.g., based on cumulative rainfall), the growing season can be broken up into multiple events.

An obvious starting point for multiple events is to examine the phenology of crop production. In general, there are three stages of crop growth: the vegetative stage from germination to panicle initiation, the reproduction phase from panicle formation to flowering, and the ripening phase from flowering to the final formation of grain. Conradt et al. (2015), Dalhaus and Finger (2016), Dalhaus et al. (2018), and Shi and Jiang (2016) have all explored models for including phenology in an index for weather insurance. Shi and Jiang (2016) created a composite index based on subperiod weather data that covers the three stages of growth. Using rice in China, the vegetative stage covered seedling, tillering, and stem elongation $(31+20+20=71$ days $)$, the reproductive phase included panicle formation through flowering $(33+8=$ 41 days), and the ripening phase covered an additional 57 days. All told, the insurable season covered 169 days. Using a two-stage procedure, they mapped discrete-time days in season for each phase and continuous time observations on rainfall, relative humidity, sunshine, and temperature to construct a parametric composite index.

Dalhaus and Finger (2016) broke the growing season into multiple parts and, using historical and observational data on crop phenology for German wheat, designed multiple event index insurance for which the farmer could choose among its "calendar" parts. They find that use of phenological observations significantly reduced basis risk. Likewise, Conradt et al. (2015) investigated a flexible index insurance plan for growing degree-days in Khazakstan. "Flexibility" in their context was to determine the beginning and end periods of the phenological growth stages (start and end dates), which vary from year to year. The advantage to weather risk management is the recognition that within-season weather patterns are not constant from year to year and will generally have different start and end dates from one year to the next. Depending upon the start and end dates signals the days over which insurance is to be calculated. In terms of phenological growth, seeds will germinate much sooner in warm years than in cold years, but if the dates for index measurement were fixed the index might weigh more heavily the effects of a cool year versus a warm year. A similar approach was deployed by Dalhaus et al. (2018) for German wheat, finding that developing WII using published phenological observations increased farmers' utility and reduced financial exposure to drought risk. The approach was to establish start and end dates of each growth stage using growing degree-days and then to accumulate rainfall within each stage to develop and structure indemnity.

These studies raise a certain number of issues for WII. Most critical is the date of growing-season onset. Maize is the dominant food crop grown in our study area, where the reference date for the beginning of long rains is 15 October. From the project baseline household survey, we found that some farmers seed early in case the rains come early whereas others withhold seeding until the rain has observably arrived. Both are rationally precautionary. However, if farmers spread seeding across a 2-week period then defining risks according to specific calendar dates is a wobbly venture. The targeting of specific events as prescribed in Turvey (2001) would be effective only if planting and weather conditions were relatively homogenous across farms in a particular heat unit isocline. Variance in weather conditions-heat and rainfall-can shift the stages across calendar date boundaries, however, rendering the ideal of specificity benign. A possible approach would be to widen the date range so that in probability the shifting patterns of weather affecting a particular stage of growth (e.g., silking in corn) would adequately be captured. From this point of view, basing WII on broader phenological stages may be a sensible approach to balancing type-I and type-II error.

Even so, it is troubling that the patterning of weather variables should be confined to proximal calendar dates of the various growth stages as if each stage could be treated as an individual and independent peril. While clearly adequate for reducing within-season basis risk, the approach does not consider overlapping perils. For example, if a late-vegetative-stage drought overlaps or spans the next stage (tillering) it is entirely possible that neither event would trigger a payout yet crop damage would be measurable. Turvey (2001) and Turvey and Norton (2008) address this problem in their specific event approach. In Turvey's (2001) Ontario, Canada, study, insurance would pay out if the rainfall in any nonoverlapping 14-day period (an event) were equal to zero, making up to four events between 1 June 
and 31 July. Turvey and Norton (2008, their Fig. 5A) defined an event when the 21-day cumulative rainfall fell below 1 in. $(2.54 \mathrm{~cm})$, making up to three events in the season.

The advantage of a specific event approach to measuring weather risk is that, by slicing the growing season into fixed day events that are overlapping in measurement but not overlapping on indemnity, there is added flexibility to capture risks within each phenological stage but also across the temporal boundaries of the phenological stages. This would further reduce the potential for type-II error, as well as type-I error. However, the specifications discussed in Turvey (2001) and Turvey and Norton (2008) are also imperfect in the sense that the nature of the event is assumed to be constant for all events (i.e., rainfall less than 1 in. in 21 days). In reality, the seasonal patterning of rainfall should not be assumed constant, nor should the triggering event. Indeed, cropping systems evolve according to the historical weather patterns that define the local ecology and growing conditions. It will be an exaggeration, for example, to treat equally Ardmore, Oklahoma-the center point of the 1930s dust bowl-and Ithaca, New York, to its northeast. From Turvey and Norton (2008), Ardmore averaged 9.08 in. of rainfall between 1 June and 31 August, whereas Ithaca averaged 10.74 in. over that period. A specific event metric that would pay out if rainfall fell below $5 \mathrm{in}$. over this period would have paid out nearly once in every 5 years $(21.21 \%$ ) in Ardmore but would never pay out in Ithaca. Likewise a specific event defined by 7 straight days with daily temperatures exceeding $90^{\circ} \mathrm{F}$ would pay out once in only 3 of 100 years in Ithaca, but would pay out on 4 or more distinct nonoverlapping events in nearly 93 of every 100 years $(92.71 \%)$ in Ardmore. While these exemplify the spatial differences that are present on a large scale, Norton et al. (2012) illustrate how basis risk correlates with differences in distance, altitude, and direction in longitude and latitude from a given weather station.

\section{Methodological framework for fractional dimensionality}

\section{a. Scaling properties and erratic weather processes}

To better understand within-season weather patterns in the context of designing weather index insurance, this section and what follows examine fractional dimensionality of weather including fractional Brownian processes and the Hurst measure. We start with Mandelbrot and Wallis (1968), who point to three characterizations of stochastic processes that might give rise to a Brownian Gauss-Markov process. The first is that some process $x(t)$ will satisfy the law of large numbers in the sense that its expected value tends to a limit $E[x(T)]$ as $T$ approaches infinity. The second is with respect to the central limit theorem in that for large $T$ the distribution around the average becomes approximately Gaussian for $T$ to infinity. The third addresses the scaling properties of the process and independent increments.

When one or more of these conditions are violated, Mandelbrot and Wallis (1968) refer to the processes as being "erratic." Thus "Joseph-erratic" might refer to a phenomenon of an extraordinary term of wetness or dryness within a time span such that localized path dependence and measurable correlations are not obscured or mitigated by the law of large numbers. "Noah-erratic" behavior occurs when the intensity of the weather event (precipitation or lack thereof) is so great as to affect the average of the measured event for many periods (e.g., years) after the event occur. Notably, both Joseph- and Noah-erratic behavior can occur simultaneously, and they feed off each other.

A first approach to considering Noah and Joseph effects is to assume that the weather patterns of interest follow a fractional Brownian motion. Mandelbrot and Van Ness (1968) detail the properties of fractional Brownian motion with considerable depth. We take a different approach to get the main points across. To get a sense of the scaling properties that might give rise to erratic behavior, consider the ordered set of measures (e.g., precipitation) $X_{T}=\left\{x_{t+S}, x_{t+S-1}, x_{t+S-2}, \ldots, x_{t}\right\}$. For convenience of illustration set $t=0$ and $S=100$. Then, the difference $x_{100}-x_{0}$ can be expressed equivalently as

$$
\begin{aligned}
x_{100}-x_{0}= & x_{100}+\left(x_{99}-x_{99}\right)+\left(x_{98}-x_{98}\right)+\cdots \\
& +\left(x_{2}-x_{2}\right)+\left(x_{1}-x_{1}\right)-x_{0} \text { or } \\
x_{100}-x_{0}= & \left(x_{100}-x_{99}\right)+\left(x_{99}-x_{98}\right)+\cdots \\
& +\left(x_{2}-x_{1}\right)+\left(x_{1}-x_{0}\right) .
\end{aligned}
$$

Assuming equivalence of any $\left(x_{t}-x_{t-1}\right)$,

$$
\begin{aligned}
E\left(x_{100}-x_{0}\right) & =E\left[\left(x_{100}-x_{99}\right)+\left(x_{99}-x_{98}\right)+\cdots+\left(x_{2}-x_{1}\right)+\left(x_{1}-x_{0}\right)\right] \\
& =E\left(x_{100}-x_{99}\right)+E\left(x_{99}-x_{98}\right)+\cdots+E\left(x_{2}-x_{1}\right)+E\left(x_{1}-x_{0}\right) \\
& =100 E\left(x_{1}-x_{0}\right) .
\end{aligned}
$$


More generally,

$$
E\left(x_{t+S}-x_{t}\right)=S E\left(x_{1}-x_{0}\right) .
$$

The variance of the differences can be expressed as

$$
\begin{aligned}
\operatorname{Var}\left(x_{t+S}-x_{t}\right)= & \sum_{t=1}^{S} E\left[\left(x_{t}-x_{t-1}\right)-E\left(x_{t}-x_{t-1}\right)\right]^{2} \\
& +\operatorname{Cov}\left(x_{t+S}-x_{t}\right)
\end{aligned}
$$

where

$$
\begin{aligned}
\operatorname{Cov}\left(x_{t+S}-x_{t}\right)= & 2 \sum_{(i \in t)=1}^{S} \sum_{(j \in t)=1}^{S} E\left[\left(x_{i}-x_{i-1}\right)-E\left(x_{i}-x_{i-1}\right)\right] \\
& \times\left[\left(x_{j}-x_{j-1}\right)-E\left(x_{j}-x_{j-1}\right)\right], \quad i \neq j .
\end{aligned}
$$

It is from this measure of variance that the scaling properties related to erratic behavior arise. The scaling can be defined by $S^{2 H}$, where $H$ is the Hurst coefficient. The Hurst coefficient plays a crucial role in the identification of fractional properties of time series. We can restate variance in terms of the Hurst scaling rule as

$$
\operatorname{Var}\left(x_{t+S}-x_{t}\right)=\operatorname{Var}\left(x_{t}-x_{t-1}\right) S^{2 H} .
$$

\section{b. Self-affine and self-similar processes}

Equation (7) holds a particular meaning to the scaling properties of Brownian motion. Self-affine refers to an invariance with respect to time scale. If $x(t, w)$ has self-affine increments with parameter $0 \leq h \leq 1$, then for a particular Brownian function

$$
B\left(t_{0}+s, w\right) \triangleq h^{-H} B\left(t_{0}+h s, w\right),
$$

where $\triangleq$ means that the two sides have the same finite joint distribution and one drawn from the same space. Thus, rewriting Eq. (7) as $\sigma_{t_{0}+S}^{2}=\sigma_{t_{0}}^{2} S^{2 H}$ and scaling by $h, \sigma_{t_{0}+h S}^{2}=\sigma_{t_{0}}^{2} h^{2 H} S^{2 H}$ or $\sigma_{t_{0}+h S}=\sigma_{t_{0}} h^{H} S^{H}$, and rescaling by $h^{-H}$ returns Eq. (7).

Self-similarity is a related property. It states that the rescaled function has the same distribution for every $T$. Again, rewriting Eq. (7) as a variance ratio, $\sigma_{t_{0}+S}^{2} / \sigma_{t_{0}}^{2}=S^{2 H}$ or $\log \left(\sigma_{t_{0}+S}^{2} / \sigma_{t_{0}}^{2}\right) / \log (S)=2 H$ so that for any particular change in the time step (e.g., $S$ ) the variance will increase at the fractional dimension rate $2 H$.

Moreover, since there is no reason to believe a priori that $\operatorname{Var}\left(x_{t}-x_{t-1}\right) \neq \operatorname{Var}\left(x_{t+1}-x_{t}\right)$ we can restate the scaled variance measure as

$$
\operatorname{Var}\left(x_{t}-x_{t-1}\right) S^{2 H}=\operatorname{Var}\left(x_{t}-x_{t-1}\right) S+\operatorname{Cov}\left(x_{t+S}-x_{t}\right),
$$

and from this we restate covariance as

$$
\operatorname{Cov}\left(x_{t+S}-x_{t}\right)=\operatorname{Var}\left(x_{t}-x_{t-1}\right)\left(S^{2 H}-S\right) .
$$

Expressed in this way, the covariance term defines the Brownian set and the nature of dependence in fractional processes. The relationships are as follows:

$$
S \Leftarrow\left\{\begin{array}{ll}
H=\frac{1}{2} \rightarrow \operatorname{Cov}\left(x_{t+S}-x_{t}\right)=0, & S=\frac{\operatorname{Var}\left(x_{t+S}-x_{t}\right)}{\operatorname{Var}\left(x_{t}-x_{t-1}\right)} \\
H>\frac{1}{2} \rightarrow \operatorname{Cov}\left(x_{t+S}-x_{t}\right)>0, & S>\frac{\operatorname{Var}\left(x_{t+S}-x_{t}\right)}{\operatorname{Var}\left(x_{t}-x_{t-1}\right)} \\
H<\frac{1}{2} \rightarrow \operatorname{Cov}\left(x_{t+S}-x_{t}\right)<0, & S<\frac{\operatorname{Var}\left(x_{t+S}-x_{t}\right)}{\operatorname{Var}\left(x_{t}-x_{t-1}\right)}
\end{array}\right\} .
$$

First, for $H=1 / 2$, the covariance term collapses to zero. In this state there is no intertemporal correlation between changes in the measure. This defines a pure Gauss-Markov, memoryless process of standard Brownian motion and the linear-in-variance assumption. Here, the variance of the measure over 100 days, months, or years is 100 times the one-step measure in days or months or years, and it appears to be predictable. This condition will satisfy all three of the characteristics identified by Mandelbrot and Wallis (1968) and is consistent with the usual interpretation of a random walk. However, for $H<1 / 2$ and $H>1 / 2$ the scaling properties are not memoryless, and thus they violate the Markov property. For $H>1 / 2$, systemic positive correlation compounds the variance so that the variance of the measure over 100 days, months, or years will be greater than 100 times the one-step measure. It is persistent. Likewise, for $H<1 / 2$, the covariance will be systemically negative so that an increase in the measure of some time scale will, in probability, reverse itself in a mean-reverting or ergodic way. The variance of the measure over 100 days, months, or years will be less than 100 times the variance of the one-step measure. 
When $H \neq 1 / 2$ the third condition is violated, and this in return gives rise to Noah- and Joseph-erratic behavior. Whether variance is expanding or contracting in scale, the process becomes far less predictable. When the process is erratic-persistent the precipitation patterns are subject to longer excursions (an excursion is a measure of the length of a stochastic process on the space of paths) in wetness and dryness; when the process is ergodic-erratic the patterns of rainfall are more oscillatory with increasingly shorter excursion paths as $H$ gets smaller.

It becomes evident then that Hurst's law has something important to add to the broader discussion of WII. We will show presently for the case of Machakos County, Kenya, in sub-Saharan Africa that indeed Hurst's law holds and in doing so violates Mandelbrot and Wallis's (1968) third condition; but equally important is our finding that the second condition-that of Gaussian-normal error around the mean path of our rainfall measure-also fails.

\section{c. Excursion patterns}

A final consideration that merits attention for WII is excursion paths (Itô 1972, 2007; Rogers 1989; Pitman and Yor 2007). In the most general way any Brownian motion is a continuous-time process with a recurrent state. By "recurrent state" it is meant that at some unknown and random time in the future the stochastic path will return to its original state or a fixed point. The Joseph effect, for example is described by two long excursions, the first being an excursion of 7 years in which conditions are good, which is followed by 7 years in which conditions are bad. If we use the inflection point between good and bad years as a fixed-point barrier, an excursion begins and ends as it crosses this point from above or below.

There are two measures of excursion. The first referred to as "local time" and counts the number of times that the path crosses the barrier in a fixed amount of time. The second measure is the length of the excursion, referred to as "stopping time" $\tau$, which is measured by the interval between barrier crossings. These intervals are not of fixed length as the biblical reference to Joseph suggests, but are random. Itô $(1972,2007)$ has shown that the excursion point process follows a Poisson distribution, $f(\tau)=\lambda^{\tau} \mathrm{e}^{-\lambda} / \tau$ ! , with expected value $E(\tau)=\lambda$ and skewness Skew $=\lambda^{-1 / 2}$.

We assert that the relationship between mean stopping time $\lambda$ and $H$ is described by a power law of the form $\lambda=\alpha H^{\beta}$, and by substitution Skew $=H^{-(\beta / 2)} / \alpha^{1 / 2}$. Differentiating the expected stopping time and skewness yields $\partial E(\tau) / \partial H=\alpha \beta H^{\beta-1}>0$ and $\partial$ Skew $/ \partial H=$ $-\beta H^{-[1+(\beta / 2)] /} /\left(2 \alpha^{1 / 2}\right)<0$, respectively. Thus, as $H$ increases, the expected stopping time increases nonlinearly but, perhaps more important, skewness falls. In other words, for low Hurst the distribution of stopping times will be left modal and positively skewed, but as $H$ increases the stopping time increases and the distribution trends toward right modal and negative skew.

We see the implications for the design of a WII as follows: As weather patterns move toward a high Hurst state the weather conditions will become more persistent and longer in duration. If it is rainfall and the excursion is above the barrier, then rain will continue accumulating. This may be ideal for some values of $H$, but for higher values the longer the rainfall lasts the closer one gets to the Noah effect, with significant flooding. Likewise, if rainfall is decreasing below the barrier, the higher Hurst values will increase the duration of drought conditions, and with higher frequency.

Conversely, low Hurst values have much smaller excursions with frequent reversals. For low Hurst a short period of rain will be followed by a short period with no or little rain. These states may in fact be adequate to avoid drought conditions if the stopping times for rainfall, by chance, exceed the stopping times with low or no rainfall, but drought conditions can arise if the opposite were true and the stopping times of no or low rainfall, by chance, exceeded the stopping times with adequate rainfall.

\section{Data and applications}

\section{a. Fractional patterning of rainfall in study area}

Our study area, Machakos County, is a semiarid and hilly terrain in the eastern province of Kenya where we are implementing a randomized control trial (RCT) to investigate bundled, or risk-contingent, credit based on long and short rains [for details on risk-contingent credit see Shee and Turvey (2012), Shee et al. (2015), and Shee et al. (2019)]. It is generally agreed that the long rains start on 15 October and end on 15 January (Government of Kenya 2014; Shee et al. 2019). We analyze Climate Hazards Group Infrared Precipitation with Station Data (CHIRPS) (Funk et al. 2015), supported by the National Aeronautics and Space Administration and National Oceanic and Atmospheric Administration. Daily CHIRPS rainfall (satellite validated with station data) data from 1983 to January 2018 are obtained online (http://chg.geog.ucsb.edu/data/ chirps/). Typically, rainfall is not evenly distributed in a season but starts low, rises to a midseason peak, and then diminishes thereafter. In fact, the pattern appears to be uniformly described by a sixth-order polynomial across all of the subcounties that we examined. A typical pattern is illustrated in Fig. 2, for central Machakos, for 


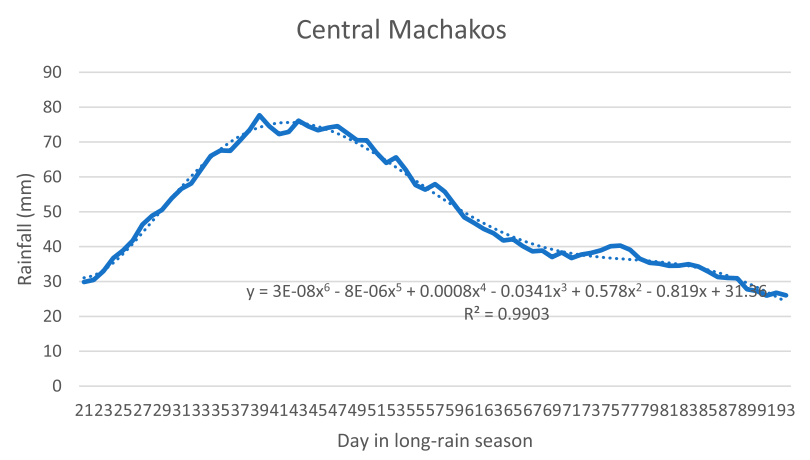

FIG. 2. The 21-day moving-average cumulative rainfall for Machakos County based on CHIRPS data: average of daily rainfall of long rain (15 Oct-15 Jan) from 15 Oct 1983 to 15 Jan 2018, with fitted sixth-order polynomial smoothing.

the average of the 21-day overlapping cumulative rainfall from 1983 to 2017. Our use of a 21-day cumulative metric serves two purposes. First, by taking a cumulative measure there is some smoothing of asynchronous rainfall patterns when it does not rain for multiple days. Second, our view is that WII is better focused on the extremes. Following Turvey (2001) and Turvey and Norton (2008) we define specific events to be 21 fixed days that are overlapping in measurement but nonoverlapping in indemnity. A shorter time scale, say 14 days, is not uncommon and is perhaps too common for a WII product that needs to sustainably balance coverage, indemnity, and premium.

Figure 3 illustrates the day-to-day probability distribution of the deviation of the recorded weather pattern from the mean (sample size $N=2478$ ). A typical assumption of randomness is that these deviations are normally distributed; however, we find that the distribution is more closely aligned with the lognormal distribution. The mean of the distribution is zero, as expected, but the skewness is 1.0123 , with kurtosis of 4.178. The modal value of -24.86 is negative, and the probability that a deviation is negative is $59.8 \%$ against $40.2 \%$ chance of a positive deviation. In other words, if 21-day cumulative rainfall is to deviate from the long-run mean, it is $50 \%$ more likely to be a negative deviation than a positive deviation.

To investigate the properties of the distribution, we compute the Hurst coefficient for each year using the scaled variance method, keeping in mind that within each year the long rain season comprises only 93 days. Our Hurst measures are based on overlapping 21-day measures, so $N=72$. Comparatively, this is a small number for estimating $H$, and therefore we should not be surprised by a wide variation in estimates. We use a time step of 8 days, which is the closest integer to the square root of 72. We compute two values, $\operatorname{Var}\left(x_{t+8}-x_{t}\right)$ and $\operatorname{Var}\left(x_{t+1}-x_{t}\right)$, and from Eq. (7)

$$
H_{S=8}=\frac{\log \left[\frac{\operatorname{Var}\left(x_{t+8}-x_{t}\right)}{\operatorname{Var}\left(x_{t+1}-x_{t}\right)}\right]}{2 \log (8)} .
$$

The year-by-year Hurst measures are provided in Fig. 3. The lowest value was $H=0.137$ (1991) and the highest was $H=0.685$ (1988). A trend analysis regressing $H$ against year showed no statistical trend in the Hurst values (significance level $p=0.61$ ). We also computed a "Hurst on Hurst" measure, using the same procedure as in Eq. (11) for the values in Fig. 4, finding that

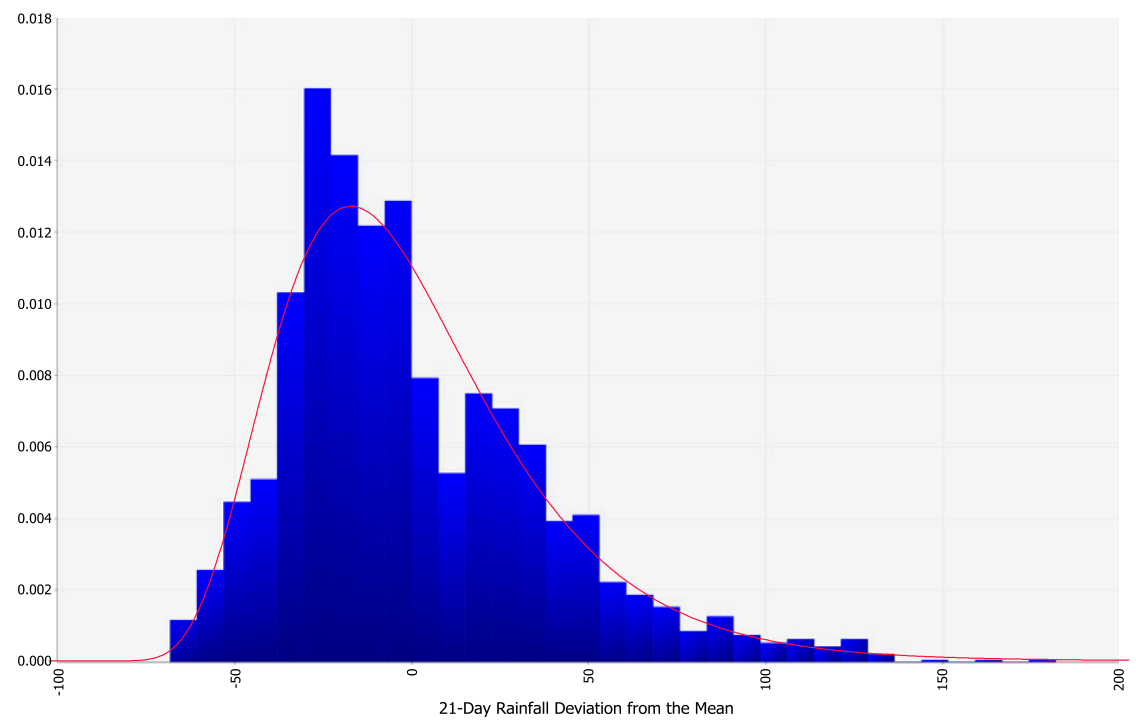

FIG. 3. Distribution of 21-day deviations from the mean. 


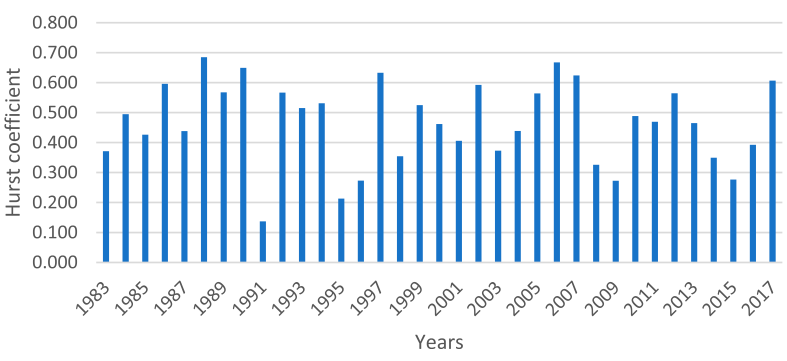

FIG. 4. Hurst coefficients for long rains in central Machakos.

$\mathrm{HoH}=0.022$, which is highly ergodic. From a practical point of view this suggests, with high probability, that a low $H$ will be followed by a higher $H$, and vice versa. This is a surprising result. In the absence of a theory, one would think that year-over-year weather patterns would be statistically independent of each other, yielding a $\mathrm{HoH}$ value around 0.5 . This does not appear to be the case. Thus, not only do our data indicate strong patterns of within-year fractionality, but they indicate that the patterns themselves are fractal. Exploring this result further is beyond the scope of this paper.

Figure 5 shows the scatterplot and power functions for cumulative rainfall (coefficient of variation $R^{2}=0.1064$ ) and damage intensity $\left(R^{2}=0.1154\right)$ with the Hurst coefficients. The damage intensity is taken from our measure of indemnity using a dynamic trigger as discussed in section 5 , but for now it shows that a $1 \%$ increase in the Hurst coefficient corresponds on average to an increase in "damage" of $0.717 \%(p=0.046)$. Similarly, a $1 \%$ increase in the Hurst coefficient corresponds on average to an increase cumulative rainfall by $0.3573 \%(p=0.056)$. Although the overall fit of these regressions is low, the relationships are interesting. In general, drought intensity increases with lower Hurst coefficients. The characteristic of low Hurst coefficient is that the seasonal rainfall patterns are mean reverting; in other words, the intertemporal covariance relationship is negative. Thus, in drought years an increase in rainfall is more likely in probability to be followed by a shortfall in rain. In contrast the high-rainfall years with $H>0.5$ have a positive covariance, suggesting that that increases in rainfall are reinforcing.

Figure 6 provides the rainfall patterns within year, and these seldom match the expectation. The solid line below the dashed line captures rainfall deficits from the mean, and for $1998(H=0.354), 2008(H=0.326)$, and $2017(H=0.607)$ early- and late-season droughts of consequence can be observed. In comparison, 1992 $(H=0.567)$ follows the average path with a late-season rainfall in excess of the average, whereas the rainfall in $1997(H=0.633)$ exceeded the average over most time periods. The main point, of course, is that rainfall deficits can arise randomly throughout the season, causing crop damage not only within a phenological stage, but also across phenological stages. They also show short-term path dependency in the various excursion patterns illustrated. These excursion paths, and patterns, rise above and fall below the cumulative mean rainfall. Our interest is in managing the risks when cumulative 21-day rainfall has an excursion below this "barrier." Our approach is discussed in the next section.

\section{b. Resolving Noah and Joseph effects with a dynamic trigger index insurance}

In the previous sections we described the fractionality in within-season rainfall patterns. The range of Hurst coefficients gives rise to observable and measurable excursions below the long-run overlapping 21-day cumulative rainfall measures from 1983 to 2017. How to recognize and incorporate these excursions into a WII model is discussed in this section. The background to this assessment is the results from an RCT to implement an insurance-linked credit product called risk-contingent
Seasonal Rainfall and Hurst Coefficient

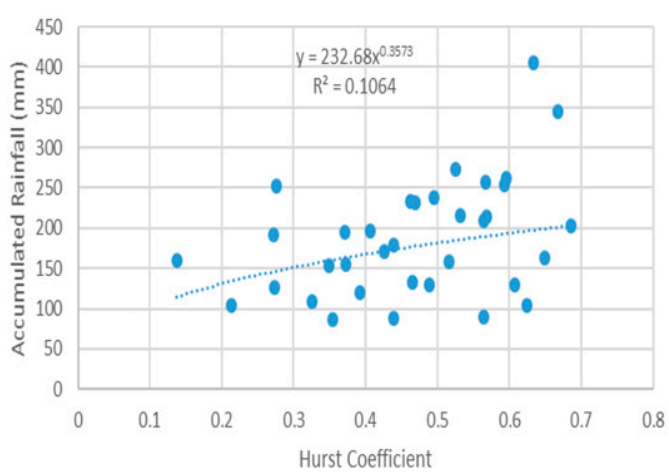

Damage Intensity and Hurst Coefficient

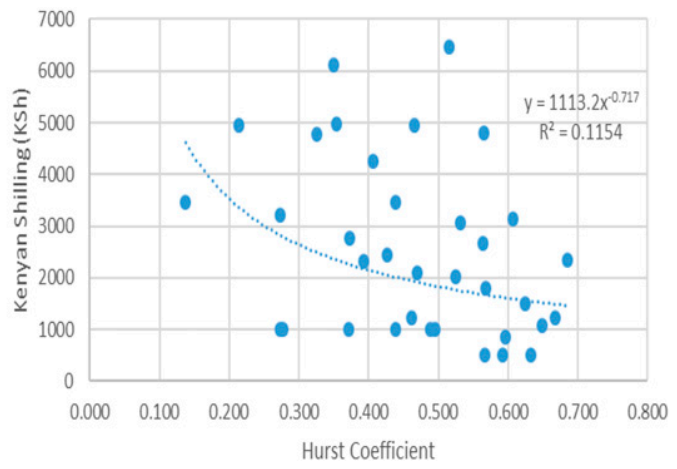

FIG. 5. Seasonal rainfall and insurance indemnity with Hurst coefficients. 
1983
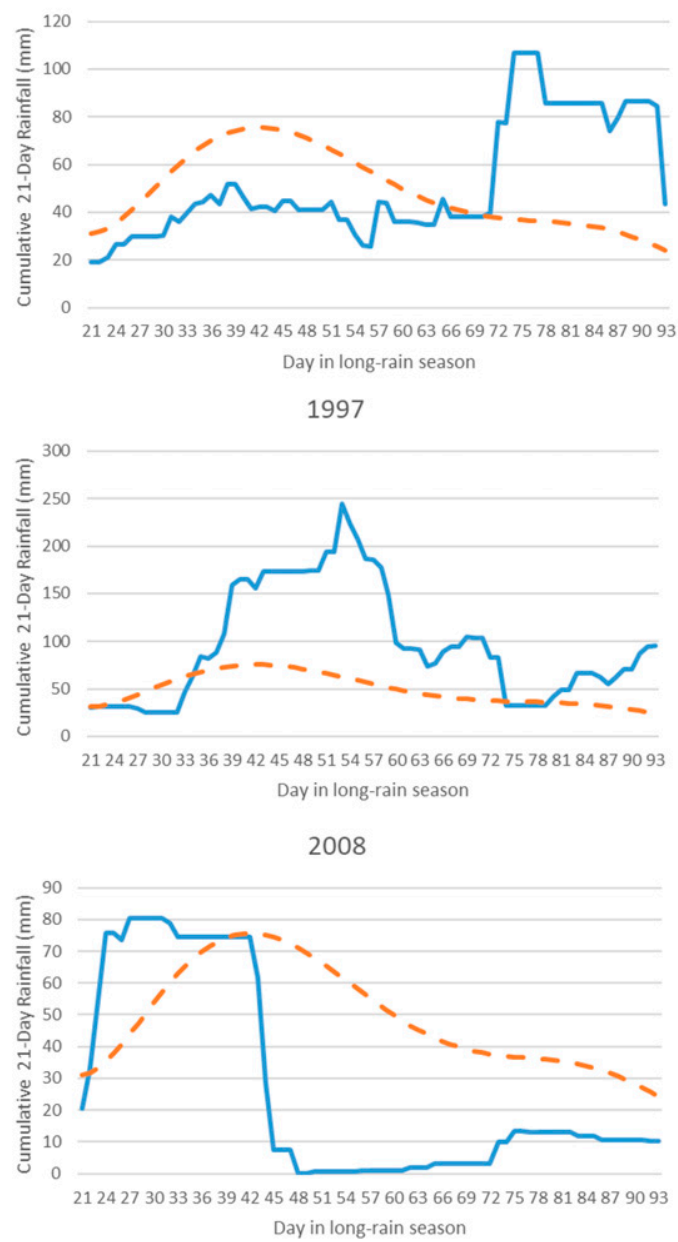

1992

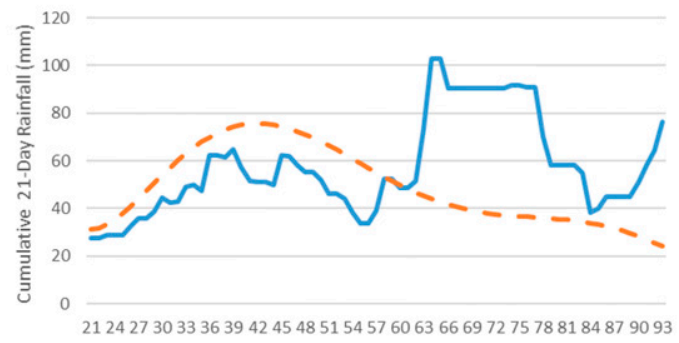

Day in long-rain season

1998

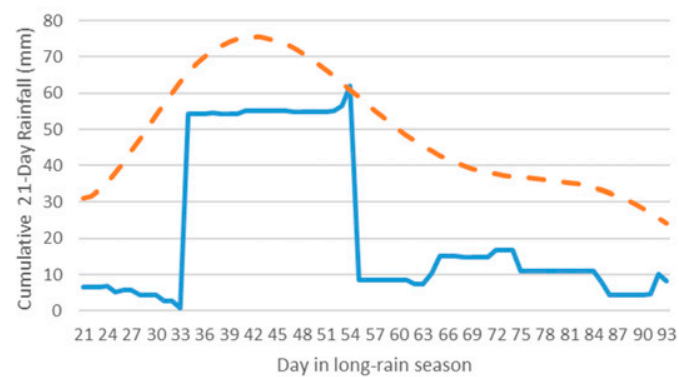

2017

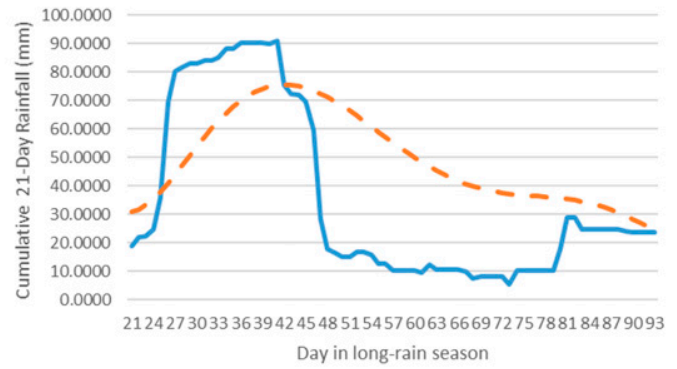

FIG. 6. Cumulative 21-day rainfall measures in comparison with average 21-day measure, 1983-2017. The solid line represents moving 21-day rainfall, and the dashed line represents the dynamic trigger. Years $1983(H=0.371)$ and $1992(H=0.567)$ were years of adequate rainfall. The year $1997(H=0.633)$ had the highest recorded seasonal rainfall $(405 \mathrm{~mm})$, and $1998(H=0.354)$ had the lowest seasonal rainfall $(86.9 \mathrm{~mm})$. The years $1998(H=0.354)$, $2008(H=0.326)$, and $2017(H=0.607)$, as illustrated, were among the worst drought years in $1983-2017$ in Machakos County.

credit (RCC) in 2017 to unbanked farmers in Machakos County [for details of the study see Shee et al. (2015)]. The RCC product was in the form of a loan, which paid an indemnity if the accumulated rainfall between 15 October and 15 January (the long rains) fell below a rainfall trigger established in millimeters below the 15 th percentile, or for an event that might occur about once in every 7 years. In our RCT design, 1150 sample households were randomly assigned to one of three research groups: treatment 1 (farmers assigned to receive traditional credit; 350 households), treatment 2 (farmers assigned to receive RCC; 350 households) or control (farmers assigned to receive no credit; 350 households).The simplicity of the design was intentional. The subject farmers had largely no interaction with formal banking services, let alone credit, and had no experience with weather (or any type of crop-related) insurance. However, in pre-experiment focus groups with farmers across the Machakos district, it was clear that failures of the rain (lack of rainfall or rainfall not occurring in a timely manner) were the biggest risks faced, and lenders also acknowledged that failure of the rain was the largest impediment to providing agricultural credit. Although we were aware of erratic weather patterns it was felt by the research team, local bank, and local insurer that a simple design for a first-time pilot of a new bundled credit product would be the least-complicated approach, with product modifications and scaling up to follow.

Weather conditions in 2017 are depicted in the lower-right panel of Fig. 5, where a significant negative 


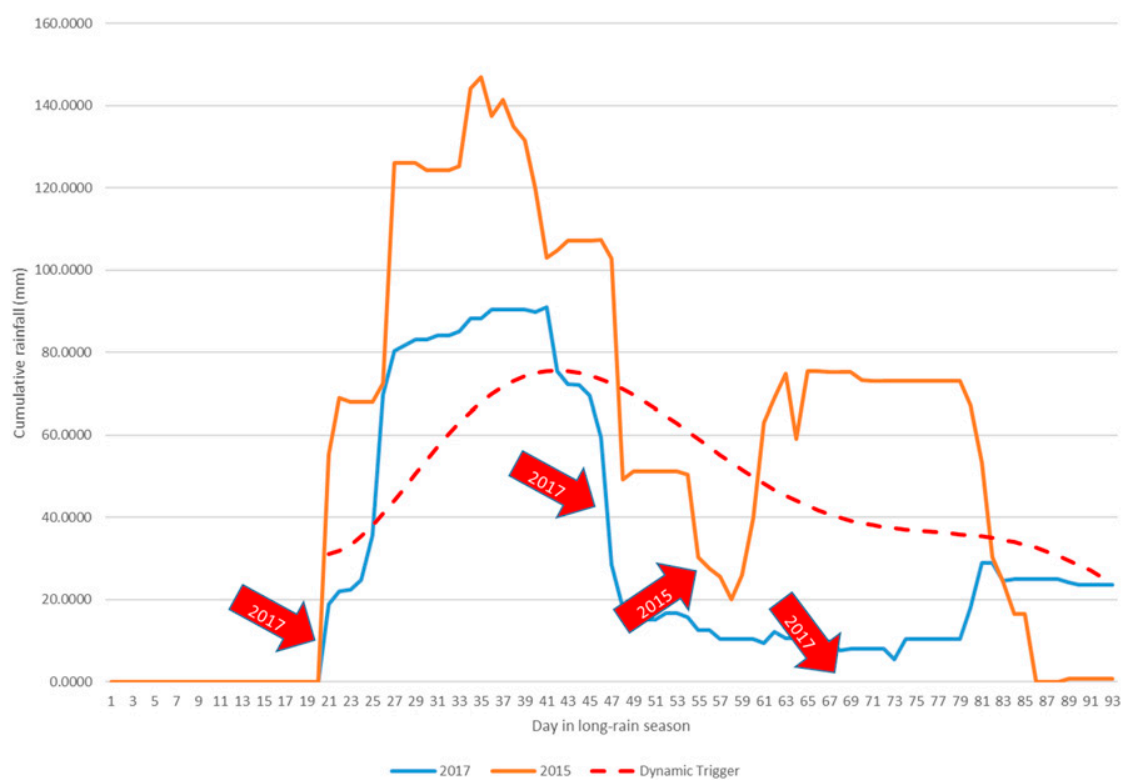

FIG. 7. Dynamic trigger rainfall insurance for long rain in central Machakos in 2015 and 2017. The blue line represents moving 21-day rainfall for 2017, the orange line shows moving 21-day rainfall for 2015, and arrows represent the days on which an event is triggered.

excursion developed and the rains dropped below $20 \mathrm{~mm}$ between vegetative and flowering/maturity stages, resulting in yield declines of more than $50 \%$ for many borrower farmers. However, because of high midseason rainfall the insurance did not trigger. Fortunately, we had anticipated that possibility and used reserve funds to provide an indemnity equal to $50 \%$ of loan balances for those receiving RCC but no indemnity for those receiving traditional loans.

For WII to be sustainable in the target area (and more generally in sub-Saharan Africa), an approach was needed that accounted for the fractional nature of rainfall discussed above. Although we find strong evidence of Noah- and Joseph-erratic phenomena in our subject area, that fact does not imply that the weather risks are uninsurable. It does mean that in the traditional sense that simplified measures-including our own 2017-18 cumulative rainfall model-will in many instances fail in the most basic efficiency measure of minimizing type-I error (which is costly to the insurer) and type-II error (which is costly to the farmer). Thus, there is a need to rethink insurance risks and indemnity structures. To confront the problems of fractional weather patterns as discussed above, we suggest here a different structure based on a "dynamic trigger" that tracks current rainfall relative to historical norms while taking into account whether the insured year is a "high Hurst" year or a "low Hurst" year. This is discussed next.

To address the erratic nature of rainfall patterns with unpredictable excursions and to reduce temporal basis risk, we develop a 21-day event model. By "event" we refer to any 21-day period in the insured season in which accumulated rainfall falls below $60 \%$ of the average accumulated rainfall for that district over the same historical 21-day period (on a calendar basis, ignoring leap years). In general, and as depicted in Fig. 1, the pattern of rainfall is low at the beginning of the season, rises, and then decreases toward the end of the season on 15 January. The triggering event is dynamic, in the sense that it maps onto the historical rainfall pattern, rising and falling accordingly.

The effects of a dynamic trigger are illustrated in Fig. 7 for central Machakos in 2015, with one small event, and 2017, with one small event and two significant events. The green line is cumulative rainfall, the blue line is the rolling 21-day cumulative rainfall, and the red dashed line is the dynamic trigger. Arrows indicate an event in which the rolling 21-day cumulative rainfall falls below the dynamic trigger. For example, the event horizon starts first at day 1-day 21, then day 2-day 22, then day 3-day 23, and so on until the end of the season at day 73-day 93. In other words, there are 73 consecutive 21-day periods in the long rain period between 15 October and 15 January. Each period is examined to determine whether the actual rainfall was below the trigger. If not, then the next sequential 21-day period is examined, and so on. If the actual rainfall is below the corresponding trigger, an event is triggered. Subsequent events cannot be overlapping. For example, if no event is recorded at day 21 or day 22 but is recorded for day 23 , 


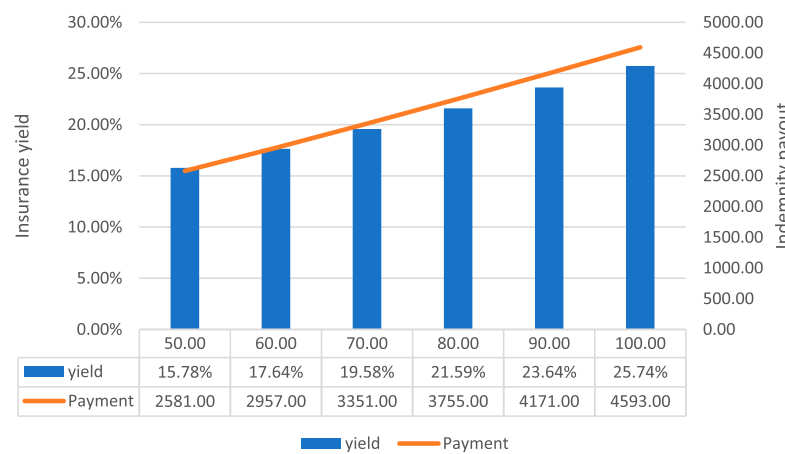

FIG. 8. Average insurance yield and indemnity payment for dynamic trigger specific event insurance.

another event cannot be recorded on day 24 . The next possible date for a second event would be day 44, covering the 21 days between day 24 and day 44. Since events cannot be overlapping, at most four events could be recorded in a single long rain season.

The rainfall deficit is measured by the difference between the rainfall trigger and actual rainfall in millimeters. Monetizing this requires multiplying the deficit (in millimeter units) by a nominal unit [Kenyan shillings (KSh) per millimeter] - the tick value-to obtain an indemnity for that event in Kenyan shillings. In our modeling we assumed that if an event was triggered, the minimal indemnity for the event was to be $500 \mathrm{KSh}$. The scheme for the dynamic trigger RCC design is provided in the appendix.

Ultimately, the final premium is based on two variables, which we can then vary. The first variable is the trigger level, and the second variable is tick value. Figure 8 illustrates the average premium rate and $2017 / 18$ indemnity based on a 10,000 KSh loan holding the dynamic trigger at $60 \%$ of average and varying the tick value from 50 to $100 \mathrm{KSh} \mathrm{mm}^{-1}$. At $50 \mathrm{KSh} \mathrm{mm}^{-1}$ the insurance yield is $15.78 \%$. This increases to $25.74 \%$ for a tick of $100 \mathrm{KSh} \mathrm{mm}^{-1}$.

\section{Concluding remarks}

In assessing the hydrology of water flows in rivers, Mandelbrot and Wallis (1968) established certain properties of stochastic processes that were erratic. Although not often mentioned explicitly in the weather index insurance literature, there is a subjective reliance on the central limit theorem and an assumption that withinseason weather patterns occur randomly, but with a convergent pattern. This is a weak assumption, and we urge for exploration into fractional properties of withinseason variance and patterns of weather conditions (in our case precipitation) generally, and consideration of Joseph and Noah effects specifically. The erratic nature of weather patterns, and particularly participation, complicates the design of WII products. In this paper we investigated the erratic nature of rainfall patterns in Machakos County in Kenya and incorporated them in designing an operational insurance-linked credit product. The motivation for the paper was to ensure an optimal design of rainfall insurance that would minimize type-I and type-II error by reducing temporal basis risk.

Our findings point to an important warning sign for WII design. We find that the patterns of rainfall are indeed erratic and consistent with the Noah and Joseph descriptors discussed by Mandelbrot and Wallis (1968). The erratic nature of rainfall emerges from two statistical failings. The first is a breakdown of the convergence to a normal distribution around the mean of our 21-day rainfall measure. Instead we find that the distribution about the average is approximately lognormal, with an almost $50 \%$ higher chance of deficit rainfall below the mean than adequate rainfall above the mean. Perhaps more important is our finding that the rainfall patterns obey Hurst's law. We find that the Hurst coefficients for the average pathway is about $H=0.8$, but the range of Hurst coefficients across all years ranged from a low below $H=0.2$ and a high above $H=0.6$. The average Hurst coefficient was not significantly different from 0.5 , but this is meaningless in an insurance context.

Because of the erratic nature of rainfall, we develop a new approach to WII based upon the accumulated rainfall in any 21 -day period falling below $60 \%$ of the long- term average for that same 21-day period. We argue that this approach is more satisfactory to matching drought conditions within and between various phenological stages of crop growth. While this new approach reduces type-I and type-II error, it comes at higher cost.

Characterizing weather patterns according to their fractional properties is no easy task and should be done with longer time series data. In our case, we only had data from 1983 to 2017, which may be a limitation in this study; however, rainfall data prior to 1983 are hardly available. In addition, our within-year measures are also limited in time, but this is unavoidable given the calendar dates of the long-rain growing season investigated and the time discontinuities between growing seasons. Nonetheless, the central ideas in this paper can be expanded to other crops and regions and can be considered in future developments of WII for agriculture.

At the macrolevel, the ideas in this paper can be extended to the understanding of poverty traps. Barrett and Swallow (2006) provide an informal approach to what they refer to as "fractal poverty traps" measured 
by scaling across farm types and industry actors and across space. Their bifurcated model explains the coexistence of high and low (multiple) equilibrium levels of productivity and income and high and low rates of economic growth. The source of their fractal poverty trap is exogenous shocks and market failure, including the failure of insurance and credit markets to develop. From our results we can observe how both short- and long-run fractional excursion patterns (the Joseph effect) can break through the threshold barrier of the dynamic trigger. With multiple equilibria derived from degrees of resilience, our approach to balancing business and financial risks for smallholder farmers using risk-contingent credit would, in theory at least, provide a source of resilience that could ultimately reduce the number of low-level equilibria in an agricultural economy. How fractional weather patterns can give rise to fractional poverty traps is worthy of further study.

Last, we do not believe at this time that the Hurst coefficient can be used directly in an indemnity formula for WII. A high Hurst coefficient, as discussed in the text, can lead to both negative and positive excursion patterns, and these would have to be parsed out into a conditional probability framework. Nonetheless, we believe that viewing weather patterns and WII through this fractional lens provides at least a first step in placing within-season weather index insurance for agriculture on a more solid scientific footing.

Acknowledgments. This research was supported by the "Optimal packaging of insurance and credit for smallholder farmers in Africa" project funded by Economic and Social Research Council (ESRC)Department of International Development (DFID), grant reference ES/L012235/1. Partial support was also provided by the W. I. Myers Endowment of Cornell University. Part of this work was also undertaken under "Satellite Technologies, Innovative and Smart Financing for Food Security (SATISFy)" project funded by the Global Resilience Partnership (GRP), through the Round 1 Global Resilience Challenge, supported by the U.S. Agency for International Development. The work was also undertaken as part of the CGIAR Research Program on Policies, Institutions, and Markets (PIM) led by the International Food Policy Research Institute (IFPRI). We appreciate generous hospitality provided by our project partner Equity Bank Kenya, Ltd. The opinions expressed in this paper do not necessarily reflect the views of our donor or partners. Any errors that remain are the authors' responsibility. The authors declare that they have no conflict of interest.

\section{APPENDIX}

\section{Model Scheme for the Design of Weather Index Insurance for a Risk-Contingent Credit Product}

Let $Z_{s}$ be the dynamic trigger for any 21-day period $(\mathrm{mm}), s$ be a rolling 21-day counter, $R_{s}$ be the actual long-rain total for any 21-day period $(\mathrm{mm})$, defined as

$$
\begin{aligned}
& R_{s}=\sum_{t=1}^{21} R_{t} \rightarrow R_{1}=\sum_{t=1}^{21} R_{t}, \\
& R_{2}=\sum_{t=2}^{22} R_{t}, \ldots, R_{72}=\sum_{t=72}^{93} R_{t},
\end{aligned}
$$

and $\psi$ be the tick value $\left(\mathrm{Ksh} \mathrm{mm}^{-1}\right)$. If $R_{s}<Z_{s}$, then for the event occurring at $s$ the indemnity ${ }_{s}=\left(Z_{s}-R_{s}\right) \psi$ and the payout $(\mathrm{Ksh})=\max \left[500,\left(Z_{s}-R_{s}\right) \psi\right]$. The total indemnity is

$$
\text { total indemnity }=\sum_{k=1}^{\max =4} \max \left[500,\left(Z_{s \rightarrow k}-R_{s \rightarrow k}\right) \psi\right]
$$

The insurance premium rate $\theta$ will then be defined as

$$
\theta=\frac{E\left\{\sum_{k=1}^{\max =4} \max \left[500,\left(Z_{s \rightarrow k}-R_{s \rightarrow k}\right) \psi\right]\right\}}{10000} .
$$

If $f$ is the loan principal (Ksh) and is equal to the loan request + the insurance premium, that is, is equal to the loan request $\times(1+\theta), r$ is the effective annual interest rate, and $T$ is the time to loan repayment, then the farmer repayment is defined as

farmer repayment

$$
=f\left(1+\frac{r}{T}\right)-\sum_{k=1}^{\max =4} \max \left[500,\left(Z_{s \rightarrow k}-R_{s \rightarrow k}\right) \psi\right] .
$$

\section{REFERENCES}

Barrett, C. B., and B. M. Swallow, 2006: Fractal poverty traps. World Dev., 34, 1-15, https://doi.org/10.1016/j.worlddev.2005.06.008. and Coauthors, 2007: Poverty traps and climate risk: Limitations and opportunities of index-based risk financing. Columbia University International Research Institute for Climate and Society Tech. Rep. 07-02, 56 pp., https://doi.org/ 10.2139/ssrn.1141933.

Binswanger-Mkhize, H. P., 2012: Is there too much hype about index-based agricultural insurance? J. Dev. Stud., 48, 187-200, https://doi.org/10.1080/00220388.2011.625411.

Carter, M. R., L. Cheng, and A. Sarris, 2011: The impact of interlinked index insurance and credit contracts on financial market deepening and small farm productivity. Annual Meeting 
of the Agricultural and Applied Economics Association, Pittsburgh PA, Agricultural and Applied Economics Association, 33 pp., http://www2.aueb.gr/conferences/Crete2012/ papers/papers \%20senior/Sarris.pdf.

,-- , and -2016 : Where and how index insurance can boost the adoption of improved agricultural technologies. J. Dev. Econ., 118, 59-71, https://doi.org/10.1016/j.jdeveco.2015.08.008.

Chantarat, S., A. G. Mude, C. B. Barrett, and M. R. Carter, 2013: Designing index-based livestock insurance for managing asset risk in northern Kenya. J. Risk Insur., 80, 205-237, https:// doi.org/10.1111/j.1539-6975.2012.01463.x.

,,--- , and C. G. Turvey, 2017: Welfare impacts of index insurance in the presence of a poverty trap. World Dev., 94, 119-138, https://doi.org/10.1016/j.worlddev.2016.12.044.

Clarke, D. J., and D. Grenham, 2013: Microinsurance and natural disasters: Challenges and options. Environ. Sci. Policy, 27, S89-S98, https://doi.org/10.1016/j.envsci.2012.06.005.

Collier, B., A. L. Katchova, and J. R. Skees, 2011: Loan portfolio performance and El Niño, an intervention analysis. Agr. Financ. Rev., 71, 98-119, https://doi.org/10.1108/00021461111128183.

Conradt, S., R. Finger, and M. Sporri, 2015: Flexible weather index-based insurance design. Climate Risk Manage., 10, 106-117, https://doi.org/10.1016/j.crm.2015.06.003.

Dalhaus, T., and R. Finger, 2016: Can gridded precipitation data and phenological observations reduce basis risk of weather index-based insurance? Wea. Climate Soc., 8, 409-419, https:// doi.org/10.1175/WCAS-D-16-0020.1.

- O. Musshoff, and R. Finger, 2018: Phenology information contributes to reduced temporal basis risk in agricultural weather index insurance. Sci. Rep., 8, 46, https://doi.org/ 10.1038/s41598-017-18656-5.

Funk, C., and Coauthors, 2015: The Climate Hazards Infrared Precipitation with Stations-A new environmental record for monitoring extremes. Sci. Data, 2, 150066, https://doi.org/ 10.1038/sdata.2015.66.

Giné, X., and D. Yang, 2009: Insurance, credit, and technology adoption: Field experimental evidence from Malawi. J. Dev. Econ., 89, 1-11, https://doi.org/10.1016/j.jdeveco.2008.09.007.

Government of Kenya, 2014. Kenya: Situation analysis for a national agricultural insurance policy (NAIP). Government of Kenya Ministry of Agriculture, Livestock and Fisheries Rep.

Heimfarth, L. E., and O. Musshoff, 2011: Weather index-based insurances for farmers in the North China Plain: An analysis of risk reduction potential and basis risk. Agr. Financ. Rev., 71, 218-239, https://doi.org/10.1108/00021461111152582.

—_, R. Finger, and O. Musshoff, 2012: Hedging weather risk on aggregated and individual farm-level: Pitfalls of aggregation biases on the evaluation of weather index-based insurance. Agr. Financ. Rev., 72, 471-487, https://doi.org/ 10.1108/00021461211277295.

Hurst, H. E., 1951: Long term storage capacity of reservoirs. Trans. Amer. Soc. Civ. Eng., 116, 770-799.

Itô, K., 1972: Poisson point processes attached to Markov processes. Proc. Sixth Berkeley Symp. on Mathematical Statistics and Probability, Vol. 3, University of California, Berkeley, 225-239.

_- 2007: Memoirs of my research on stochastic analysis. Stochastic Anal. Appl., 2, 1-6.

Jensen, N. D., C. B. Barrett, and A. G. Mude, 2016: Index insurance quality and basis risk: Evidence from northern Kenya. Amer. J. Agric. Econ., 98, 1450-1469, https://doi.org/10.1093/ajae/ aaw046.

Karlan, D., E. Kutsoati, M. McMillan, and C. Udry, 2011: Crop price indemnified loans for farmers: A pilot experiment in rural Ghana. J. Risk Insur., 78, 37-55, https://doi.org/10.1111/ j.1539-6975.2010.01406.x.

Khalil, A. F., H. H. Kwon, U. Lall, M. J. Miranda, and J. R. Skees, 2007: El Niño-Southern Oscillation-based index insurance for floods: Statistical risk analyses and application to Peru. Water Resour. Res., 43, W10416, https://doi.org/10.1029/ 2006WR005281.

Mahul, O., and J. R. Skees, 2007: Managing agricultural risk at the country level: The case of index-based livestock insurance in Mongolia. World Bank Policy Research Working Paper 4325, $37 \mathrm{pp}$.

Makaudze, E. M., and M. J. Miranda, 2010: Catastrophic drought insurance based on remotely sensed normalized difference vegetation index for smallholder farmers in Zimbabwe. Agrekon, 49, 418-432, https://doi.org/10.1080/03031853.2010.526690.

Mandelbrot, B., and J. W. Van Ness, 1968: Fractional Brownian motions, fractional noises and applications. SIAM Rev., 10, 422-437, https://doi.org/10.1137/1010093.

__ , and J. R. Wallis, 1968: Noah, Joseph, and operational hydrology. Water Resour. Res., 4, 909-918, https://doi.org/ 10.1029/WR004i005p00909.

Marr, A., A. Winkel, M. van Asseldonk, R. Lensink, and E. Bulte, 2016: Adoption and impact of index-insurance and credit for smallholder farmers in developing countries: A systematic review. Agr. Financ. Rev., 76, 94-118, https://doi.org/10.1108/ AFR-11-2015-0050.

Miranda, M. J., and C. Gonzalez-Vega, 2011: Systemic risk, index insurance, and optimal management of agricultural loan portfolios in developing countries. Amer. J. Agric. Econ., 93, 399-406, https://doi.org/10.1093/AJAE/AAQ109.

Mishra, K., R. Gallenstein, A. G. Sam, and M. J. Miranda, 2018: The impact of index-insured loans on agricultural production in Northern Ghana. Proc. Annual Meeting of the Agricultural and Applied Economics Association, Washington, DC, Agricultural and Applied Economics Association, Paper 274251, http://ageconsearch.umn.edu/record/274251/ files/Abstracts_18_05_18_11_15_40_07_68_194_29_186_0.pdf.

Muller, B., L. Johnson, and D. Kreuer, 2017: Maladaptive outcomes of climate insurance in agriculture. Global Environ. Change, 46, 23-33, https://doi.org/10.1016/j.gloenvcha.2017.06.010.

Norton, M. T., C. G. Turvey, and D. Osgood, 2012: Quantifying spatial basis risk for weather index insurance. J. Risk Finance, 14, 20-34, https://doi.org/10.1108/15265941311288086.

Pelka, N., O. Musshoff, and R. Weber, 2015: Does weather matter? How rainfall affects credit risk in agricultural microfinance. Agric. Financ. Rev., 75, 194-212, https://doi.org/ 10.1108/AFR-10-2014-0030.

Pitman, J., and M. Yor, 2007: Itô's excursion theory and its applications. Japan. J. Math., 2, 83-96, https://doi.org/10.1007/ s11537-007-0661-z.

Richards, T. J., J. Eaves, V. Fournier, S. E. Naranjo, C.-C. Chu, and T. J. Henneberry, 2006: Managing economic risk caused by insects: Bug options. Agr. Financ. Rev., 66, 27-45, https:// doi.org/10.1108/00214660680001178.

Rogers, L. C. G., 1989: A guided tour through excursions. Bull. London Math. Soc., 21, 305-341, https://doi.org/10.1112/blms/ 21.4.305.

Shee, A., and C. G. Turvey, 2012: Collateral-free lending with riskcontingent credit for agricultural development: Indemnifying loans against pulse crop price risk in India. Agric. Econ., $\mathbf{4 3}$, 561-574, https://doi.org/10.1111/j.1574-0862.2012.00603.x.

- — - and J. D. Woodard, 2015: A field study for assessing risk-contingent credit for Kenyan pastoralists and dairy 
farmers. Agric. Financ. Rev., 75, 330-348, https://doi.org/ 10.1108/AFR-07-2015-0030.

, and L. You, 2019: Design and rating of risk-contingent credit for balancing business and financial risks for Kenyan farmers. Appl. Econ., 51, 5447-5465, https://doi.org/10.1080/ 00036846.2019 .1613502$.

Shi, H., and Z. Jiang, 2016: The efficiency of composite weather index insurance in hedging rice yield: Evidence from China Agric. Econ., 47, 319-328, https://doi.org/10.1111/agec.12232.

Skees, J. R., and B. J. Barnett, 2006: Enhancing microfinance using index-based risk-transfer products. Agric. Finance Rev., 66, 235-250, https://doi.org/10.1108/00214660680001189.

Turvey, C. G., 2001: Weather derivatives for specific event risks in agriculture. Rev. Agric. Econ., 23, 333-351, https://doi.org/ 10.1111/1467-9353.00065.
— , and M. Norton, 2008: An Internet tool for weather risk management. Agric. Resour. Econ. Rev., 37, 63-78, https:// doi.org/10.1017/S106828050000215X.

von Negenborn, F., R. Weber, and O. Musshoff, 2018: Explaining weather-related credit risk with evapotranspiration and precipitation indices. Agric. Finance Rev., 78, 246-261, https:// doi.org/10.1108/AFR-07-2017-0058.

Woodard, J. D., and P. Garcia, 2008: Basis risk and weather hedging effectiveness. Agric. Finance Rev., 68, 99-117, https:// doi.org/10.1108/00214660880001221.

-, A. Shee, and A. Mude, 2016: A spatial econometric approach to designing and rating scalable index insurance in the presence of missing data. Geneva Pap. Risk Insur. Issues Pract., 41, 259-279, https://doi.org/10.1057/ gpp.2015.31. 